\section{Spectral Filters Influence}

\section{Transpirational Water Loss in Chrysanthemum}

\author{
Nihal C. Rajapakse and John W. Kelly \\ Department of Horticulture, Clemson University, Clemson, SC 29634-0375
}

Additional index words. Dendranthema $\times$ grandiflorum, light quality, water loss, growth regulation

\begin{abstract}
Transpiration rates of chrysanthemum [Dendranthema xgrandiflorum (Ramat.) Kitamura] plants grown under spectral filters were evaluated as part of an investigation on using light quality to regulate plant growth. The $6 \% \mathrm{CuSO}_{4} \cdot 5 \mathrm{H}_{2} \mathrm{O}$ spectral filter reduced photosynthetic photon flux density in red (R) and far red (FR) wavelengths and increased the $R$ : FR and blue $(B): R$ ratios $(B=400$ to $500 \mathrm{~nm} ; R=600$ to $700 \mathrm{~nm} ; \mathrm{FR}=$ 700 to $800 \mathrm{~nm}$ ) of transmitted light relative to the water (control) filter. After 28 days, cumulative water use of plants grown under $\mathrm{CuSO}_{4}$ filters was $\approx 37 \%$ less than that of control plants. Transpiration rates were similar among plants grown under $\mathrm{CuSO}_{4}$ and control filters when expressed as leaf area, a result suggesting that the reduced cumulative water loss was a result of smaller plant size. Plants grown under $\mathrm{CuSO}_{4}$ filters had slightly lower (10\%) stomatal density than control plants. Light transmitted through $\mathrm{CuSO}_{4}$ filters did not alter the size of individual stomata; however, total number of stomata and total stomatal pore area per plant was $\approx 50 \%$ less in plants grown under $\mathrm{CuSO}_{4}$ filters than in those grown under control filters due to less leaf area. The results suggest that altering light quality may help reduce water use and fertilizer demands while controlling growth during greenhouse production.
\end{abstract}

Chemical growth regulators commonly are used in horticulture to reduce plant height and maintain high-quality plants during marketing. Chemical growth regulators also have increased leaf chlorophyll content (Starman et al., 1990), reduced leaf area (Wang and Gregg, 1989), reduced plant water use (Steinberg et al., 1991a, 1991b), and improved plant establishment in the field (Latimer, 1991). However, recent restrictions on using certain growth-regulating chemicals on horticultural crops and increasing environmental awareness have stimulated interest in using nonchemical alternatives to regulate plant growth.

Various nonchemical methods, such as manipulating greenhouse temperature and light quality have been investigated (Heins and Erwin, 1990; McMahon and Kelly, 1990; Mortensen and Stromme, 1987). Our experiments with spectral filters to alter light quality indicated that light transmitted through $\mathrm{CuSO}_{4}$ filters reduced plant height and intemode length in a manner similar to chemical growth regulators in various horticultural plants (Benson and Kelly, 1991; McMahon and Kelly, 1990; Rajapakse and Kelly, 1992). Rigid or flexible plastic greenhouse covers with specific spectral qualities would enable growers to use light quality to regulate the growth of greenhouse crops.

\footnotetext{
Received for publication 15 Mar. 1993. Accepted for publication 18 May 1993. Technical contribution no. 3415 of the South Carolina Agricultural Experiment Station. The cost of publishing this paper was defrayed in part by the payment of page charges. Under postal regulations, this paper therefore must he hereby marked advertisement solely to indicate this fact.
}

Reduced water use may bean added benefit of $\mathrm{CuSO}_{4}$ filters. Water loss from a plant mainly takes place through stomata, therefore, the number of stomata and their aperture influence plant water loss. Red (R) light has induced stomatal opening and far red (FR) light has induced stomatal closure, a result suggesting that phytochromes are involved in stomatal movement (Roth-Bejerano and Itai, 1981). In previous experiments, we showed that $\mathrm{CuSO}_{4}$ spectral filters reduced irradiance in $\mathrm{R}$ and FR wavelengths of transmitted light (Rajapakse and Kelly, 1992) and that the plant's response under $\mathrm{CuSO}_{4}$ filters may be regulated by phytochromes (Rajapakse et al., 1993). The reduced irradiance in $\mathrm{R}$ and FR wavelengths under $\mathrm{CuSO}_{4}$ filters may reduce stomatal aperture, thus reducing plant transpiration rate and cumulative water use. Therefore, in the present study, we evaluated the influence of $\mathrm{CuSO}_{4}$ spectral filters on water use and transpiration of chrysanthemum plants.

Uniformly rooted 'Bright Golden Anne' chrysanthemum shoot cuttings with three to four leaves (Yoder Brothers, Pendleton, S.C.) were planted (Sept. 1991) in $600-\mathrm{cm}^{3}(11-\mathrm{cm})$ square plastic pots containing 60 to $70 \mathrm{~g}$ (dry weight) commercial potting mix (Mix 3B; Fafard, Anderson, S.C.). Plants were grown as single-stem plants in a greenhouse for 10 days before being subjected to the light treatments. All plants were fertilized once daily at irrigation with $18 \mathrm{~N}-3.5 \mathrm{P}-5 \mathrm{~K}(\mathrm{mM})$ from Peter's 20-20-20 fertilizer (W.R. Grace Co., Fogelsville, Pa.).

After the 10-day establishment period, plants were transferred to growth chambers with $6 \% \mathrm{CuSO}_{4} \cdot 5 \mathrm{H}_{2} \mathrm{O}(\mathrm{w} / \mathrm{v})$ or water (control) "fluid roofs" (spectral filters) (Rajapakse and
Kelly, 1992). The inside walls of each chamber were covered with white and the outside walls with black polyethylene to prevent the transmission of unfiltered natural radiation into the chambers. Two fans at opposite sides of each chamber circulated air through the chamber and prevented heat build up. The chambers were placed inside a glasshouse. Days inside the $\mathrm{CuSO}_{4}$ or control chambers averaged $25 \pm 4 \mathrm{C}$ and nights $20 \pm 3 \mathrm{C}$.

The spectral photon flux density (PFD) ( 350 to $850 \mathrm{~nm}$ in 5 -nm increments) inside each growth chamber was measured at the beginning and end of the experiment with a spectroradiometer fitted with a remote cosine sensor (models LI-1800 and LI-1800-10, respectively; LI-COR, Lincoln, Neb.). Radiation measurements were made between 1200 and 1400 HR on cloudless days. Radiation measurements indicated that spectral quality did not change during the experiment. The $\mathrm{CuSO}_{4}$ filters reduced $\mathrm{R}$ and FR wavelengths of transmitted radiation compared to the control filters (Rajapakse and Kelly, 1992). Photosynthetic photon flux density (PPFD) inside the growth chambers was determined with a quantum meter fitted with a quantum sensor (models LI-185 and LI-190SA, respectively; LI-COR). PPFD under $\mathrm{CuSO}_{4}$ filters was reduced by $\approx 33 \%$ compared to that under control filters. A neutral shading material (cheesecloth) was placed over the control filter to ensure the same PPFD as in the $\mathrm{CuSO}_{4}$ chamber. PFD ratios between 600 and 700 and 700 and $800 \mathrm{~nm}$ [R: FR], 400 and 500 and 600 and $700 \mathrm{~nm}[\mathrm{~B}: \mathrm{R}]$, and 400 and 500 and 700 and $800 \mathrm{~nm}$ [B : FR] were calculated for radiation transmitted through control and $\mathrm{CuSO}_{4}$ filters. $\mathrm{R}: \mathrm{FR}, \mathrm{B}: \mathrm{R}$, and $\mathrm{B}: \mathrm{FR}$ ratios under $\mathrm{CuSO}_{4}$ filters were 5.8, 1.6, and 9.2, respectively. Those ratios under the control filter were 1.1, 0.6 , and 0.7 , respectively.

Transpiration was measured gravimetrically during two 5-day dry-down cycles (7 to 11 days and 21 to 25 days) after placing the plants in the chambers. On the evening before the beginning of a dry-down cycle, plants were watered to field capacity and excess water was drained overnight. The following morning, pots were covered with clear plastic film to prevent direct evaporation from the medium's surface. Weights were measured daily at 0830 and $1730 \mathrm{HR}$ during each dry-down cycle. Plants were not watered during the 5-day drying cycles. Chambers were covered with a black cloth after each 1730 HR weighing. The black cloth was removed at the $0830 \mathrm{HR}$ weighing to provide a 9 -h photoperiod. Transpiration rate and cumulative water use were calculated from the weight-loss data.

Stomatal resistance of abaxial and adaxial leaf surfaces was measured with a steady-state porometer (model LI-1600; LI-COR) between 1200 and $1400 \mathrm{HR}$ on the day plants were transferred to the chambers and again on days 7,14 , and 21 in the chamber. Stomatal resistance was measured on the third or fourth fully expanded leaf from the apex of five representative plants grown in each chamber. Plants were watered to field capacity on the day before the measurements were taken. 
Total leaf area was measured at the end of the experiment (28 days) using an area meter (model LI-3100; LI-COR). Water-use efficiency (estimated as units of water used to produce one unit of dry matter) at the end of the second dry-down cycle was calculated as the average units of water consumed for production of a unit of dry matter (Kramer, 1983).

Leaf epicuticular wax development and stomatal characteristics were determined by scanning electron microscopy. At harvest (between 1100 and $1200 \mathrm{HR}$ ), the third leaf from the apex on each plant was frozen immediately in liquid $\mathrm{N}$ and freeze-dried. A leaf sample $\left(\approx 16 \mathrm{~mm}^{2}\right)$ from the middle of each leaf (avoiding the midrib) was mounted on aluminum stubs and coated with $0.02 \mu \mathrm{m}$ gold palladium and observed under a scanning electron microscope (model IC 848; JEOL, Tokyo) with an accelerating voltage of $15 \mathrm{kV}$. Stomata on the abaxial and adaxial surfaces were counted on three fields from each leaf sample (total of 15 fields per treatment). Stomatal length and width were measured on five stomata from each field (total of 75 stomata per treatment). Stomatal density per square millimeter, total number of stomata, and total pore area per plant were estimated using leaf area and stomatal measurements.

Control and $\mathrm{CuSO}_{4}$ filters were assigned randomly to four growth chambers in two replications. Five single plants were used in each treatment in replicate. Data were subjected to analysis of variance.

Cumulative water loss of plants grown under $\mathrm{CuSO}_{4}$ filters was lower than that of control plants during both dry-down cycles (Fig. $1 \mathrm{~A}$ and B). The difference in water loss between plants grown undercontrol and $\mathrm{CuSO}_{4}$ filters was greater during the second dry-down cycle, mainly due to greater leaf area of control plants (i.e., a $37 \%$ reduction in cumulative water use at the end of the second dry-down cycle compared to a $13 \%$ reduction at the end of the first cycle).

The transpiration rate per plant during the light period was significantly higher in plants grown under control than $\mathrm{CuSO}_{4}$ filters in both dry-down cycles (Fig. 2 A and B). However, the difference in transpiration rate per plant between plants grown under $\mathrm{CuSO}_{4}$ and control filters was small in the first dry-down cycle $\left(17 \%\right.$ increase in control over $\mathrm{CuSO}_{4}$ filters). The difference in transpiration rate per plant between plants grown under $\mathrm{CuSO}_{4}$ and control filters was greater during the second dry-down cycle (72\% increase in control over $\mathrm{CuSO}_{4}$ filters). Transpiration rate per plant during the night was similar between plants grown under control and $\mathrm{CuSO}_{4}$ filters, although plants grown under $\mathrm{CuSO}_{4}$ filters had smaller leaf areas than plants grown under control filters. This result indicates that plants grown under $\mathrm{CuSO}_{4}$ filters lost more water per unit area during the night, possibly due to higher cuticular transpiration or impaired stomatal closure. During the second dry-down cycle, the day and night extremes were greater in plants grown under control filters.

Stomatal resistance measured at 0,7 , or 14 days after treatment was similar for plants
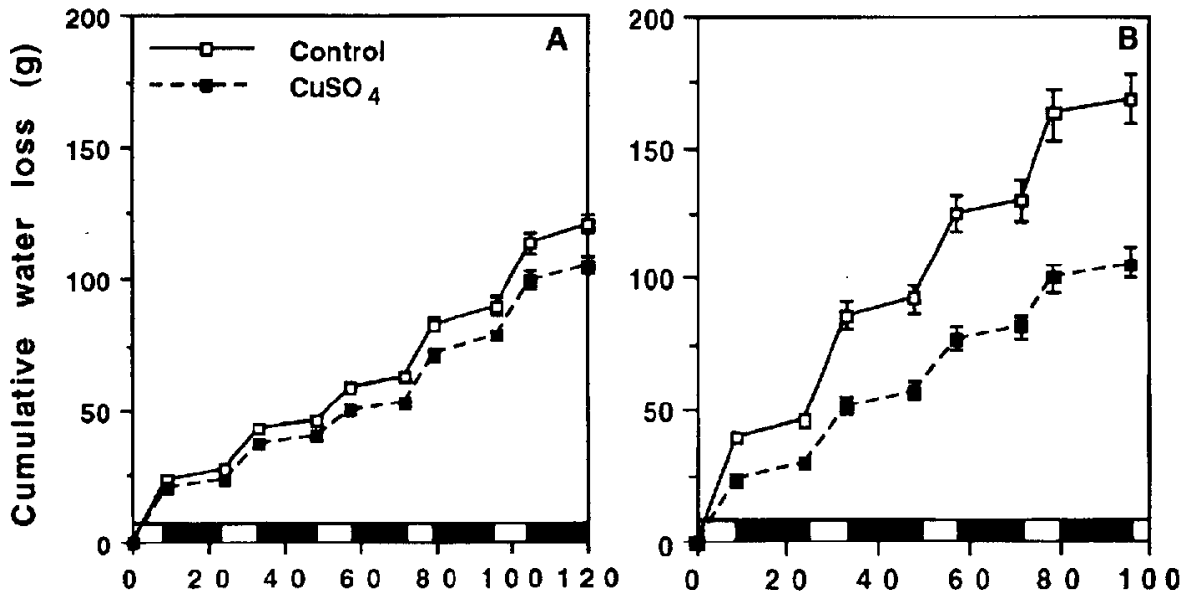

Time (h)

Fig. 1. Influence of $\mathrm{CuSO}_{4}$ or water (control) filters on cumulative water loss in chrysanthemum plants. (A) First dry-down cycle, (B) second dry-down cycle. Light and dark bands on the time axis indicate days and nights, respectively.
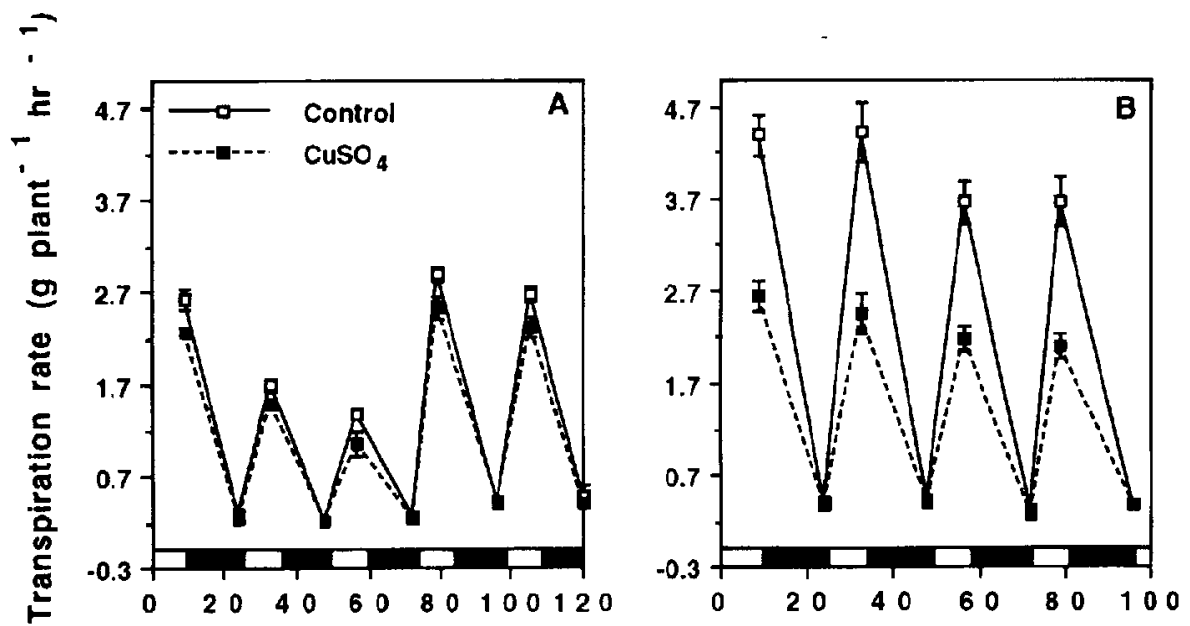

Time (h)

Fig. 2. Influence of $\mathrm{CuSO}_{4}$ or water (control) filters on water-loss rate in chrysanthemum plants. (A) First dry-down cycle, (B) second dry-down cycle. Light and dark bands on the time axis indicate days and nights, respectively.

grown under control and $\mathrm{CuSO}_{4}$ filters (data not shown). However, abaxial-surface stomatal resistance was slightly but significantly lower in plants grown under control filters $(1.7$ $\mathrm{s} \cdot \mathrm{cm}^{-1}$ for plants grown under control vs. 2.1 $\mathrm{s} \cdot \mathrm{cm}^{-1}$ for plants grown under $\mathrm{CuSO}_{4}$ filters, $P$ $\leq 0.05$ ) after 21 days in the chambers. Transpiration rate, calculated based on leaf area (at the end of second dry-down cycle), indicated that the day transpiration rate was significantly $(P$ $\leq 0.05)$ higher $(10 \%)$ in plants grown under control filters ( $5.9 \mathrm{mg} \mathrm{H} \mathrm{O} / \mathrm{cm}^{2}$ per h) than in those grown under $\mathrm{CuSO}_{4}$ filters $(5.3 \mathrm{mg} \mathrm{H} \mathrm{O} /$ $\mathrm{cm}^{2}$ per $\mathrm{h}$ ). This result agrees with the reduced stomatal resistance of plants grown under control filters. Night transpiration rate of plants grown under $\mathrm{CuSO}_{4}$ filters $\left(0.87 \mathrm{mg} \mathrm{H} \mathrm{H}_{2} \mathrm{O} / \mathrm{cm}^{2}\right.$ per h) was $\approx 33 \%$ higher than that of plants grown under control filters $\left(0.57 \mathrm{mg} \mathrm{H} \mathrm{H}_{2} \mathrm{O} / \mathrm{cm}^{2}\right.$ per h) during the second dry-down cycle $(P \leq$ $0.05)$. These findings agree with the waterloss pattern of plants treated with chemical growth regulators. Steinberg et al. (1991a) reported that Ligustrum plants treated with the chemical growth regulator (E)-1- ( $p$-chlorophenyl)-4,4-dimethyl-2-(1,2,4-triazol-1-yl)-1penten-3-ol(uniconazole) had similar transpiration rates per unit leaf area but lower cumulative water use compared with nontreated plants.

Water-use efficiency of plants grown under control filters (394) was greater than that of plants grown under $\mathrm{CuSO}_{4}$ filters $(515, P \leq$ 0.05 ). Our previous research showed that plants grown under $\mathrm{CuSO}_{4}$ filters had $\approx 38 \%$ lower dry-matter production compared to that of plants grown under control filters (Rajapakse and Kelly, 1992). Reduced water-use efficiency of plants grown under $\mathrm{CuSO}_{4}$ filters could be due to a greater reduction of drymatter accumulation compared to plants grown under control filters.

The difference in cumulative water loss and transpiration rate per plant between plants 
grown under control and $\mathrm{CuSO}_{4}$ filters maybe explained by plant and stomatal characteristics. Leaf cuticular wax development was similar in plants grown under $\mathrm{CuSO}_{4}$ and control filters (Fig. 3). Abaxial-surface stomatal density of plants grown under $\mathrm{CuSO}_{4}$ filters was slightly lower $(10 \%)$ than that of plants grown under control filters, but adaxial-surface stomatal density was similar between plants grown under control and $\mathrm{CuSO}_{4}$ filters (Table 1). Stomatal size (length, width, or pore area) was similar for plants grown under control and $\mathrm{CuSO}_{4}$ filters, a result suggesting that light transmitted through $\mathrm{CuSO}_{4}$ filters did not affect stomatal opening. Although the size of a stomate was similar for plants grown under $\mathrm{CuSO}_{4}$ and control filters, total pore area and total number of stomata per plant was $\approx 50 \%$ lower in plants grown under $\mathrm{CuSO}_{4}$ filters due to reduced total leaf area, a result that explains the lower cumulative water loss under $\mathrm{CuSO}_{4}$ filters. In contrast to present findings, the chemical growth regulators $\alpha$ - cyclopropyl $-\alpha-$ (4-methoxyphenyl)-5-pyrimidinemethanol (ancymidol) and uniconazole have increased stomatal density of sunflower (Helianthus
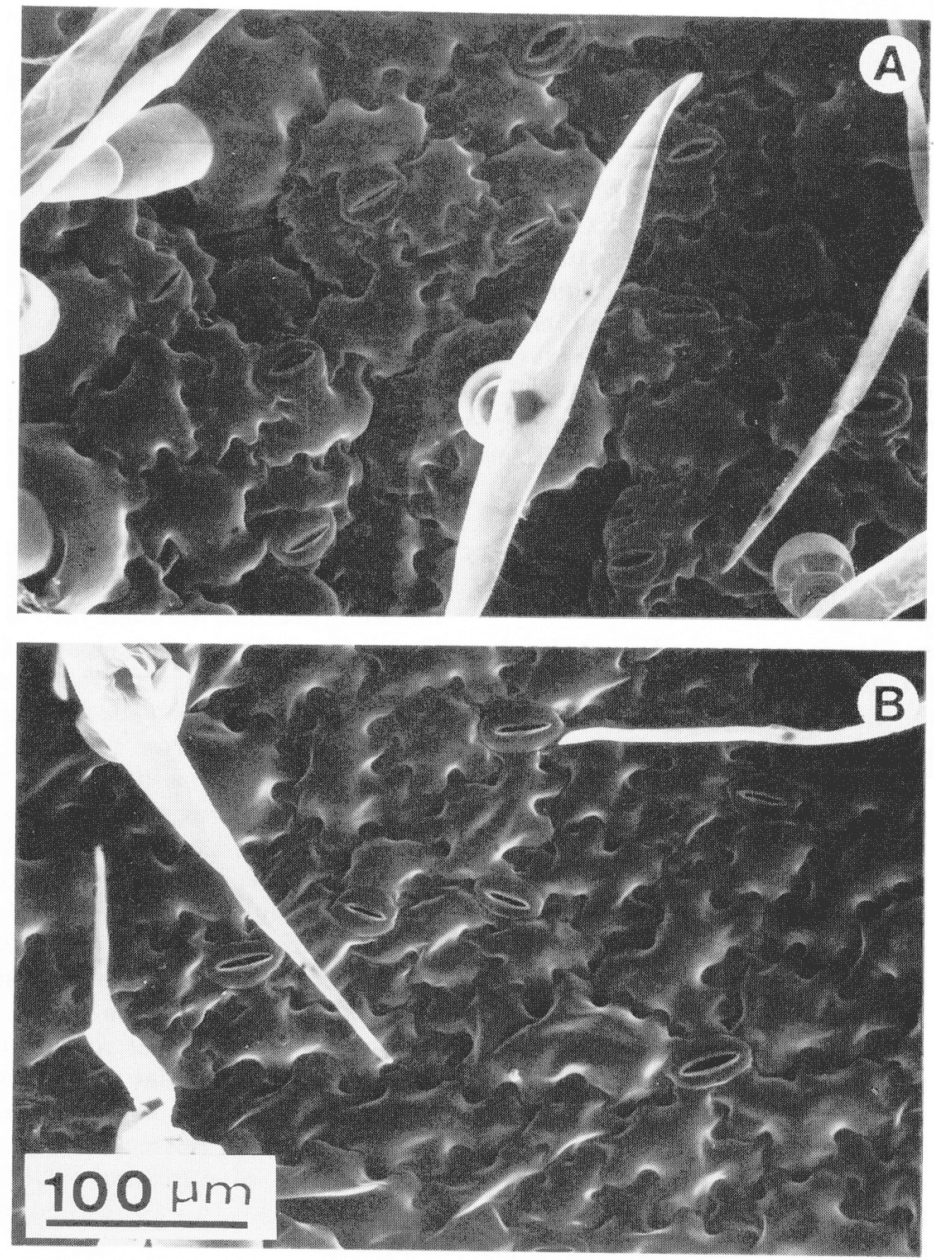

Fig. 3. Scanning electron micrographs $(\times 200)$ of abaxial leaf surface of a chrysanthemum plant grown under (A) water (control) filter or (B) $\mathrm{CuSO}_{4}$ filter.

Table 1. Influence of a $\mathrm{CuSO}_{4}$ spectral filter on stomatal characteristics of chrysanthemum plants.

\begin{tabular}{|c|c|c|c|c|c|c|c|}
\hline \multirow[b]{2}{*}{ Filter } & \multicolumn{2}{|c|}{$\begin{array}{c}\text { Surface area } \\
\text { (stomata/mm²) }\end{array}$} & \multirow{2}{*}{$\begin{array}{c}\text { Length } \\
(\mu \mathrm{m})\end{array}$} & \multirow{2}{*}{$\begin{array}{l}\text { Width } \\
(\mu \mathrm{m})\end{array}$} & \multirow{2}{*}{$\begin{array}{c}\text { Pore } \\
\text { area } \\
\left(\mu \mathrm{m}^{2}\right)\end{array}$} & \multirow{2}{*}{$\begin{array}{c}\text { Total } \\
\text { stomata } \\
\left(\times 10^{6} / \text { plant }\right)\end{array}$} & \multirow{2}{*}{$\begin{array}{c}\text { Total pore } \\
\text { area } \\
\text { (mm } \mathrm{mm}^{2} / \text { plant) }\end{array}$} \\
\hline & Abaxial & Adaxial & & & & & \\
\hline Control & $61 a^{z}$ & $10 \mathrm{a}$ & $26.7 \mathrm{a}$ & $5.3 \mathrm{a}$ & $449.8 \mathrm{a}$ & $4.8 \mathrm{a}$ & 2129 a \\
\hline $\mathrm{CuSO}_{4}$ & $55 \mathrm{~b}$ & $10 a$ & $27.3 \mathrm{a}$ & $4.8 \mathrm{a}$ & $412.6 \mathrm{a}$ & $2.6 \mathrm{~b}$ & $1056 \mathrm{~b}$ \\
\hline
\end{tabular}

${ }^{z}$ Means with same letter are not significantly different at $P \leq 0.05$.

annuus L.) (Starman et al., 1990) and Ligustrum japonicum Thunb. (Steinberg et al., 1991a), respectively. However, transpiration rate per unit leaf area did not increase in gowthregulator-treated plants due to reduced stomatal aperture (Orton and Mansfield, 1976) or suppressed xylem development (Wang and Gregg, 1989).

Our results suggest that the quality of light transmitted through $\mathrm{CuSO}_{4}$ filters could reduce water loss in chrysanthemum plants and reduce plant height and leaf area. Reduced water loss was a result of reduced plant size under $\mathrm{CuSO}_{4}$ filters. However, the postproduction quality of chrysanthemum plants grown under $\mathrm{CuSO}_{4}$ filters remains to be determined.

\section{Literature Cited}

Benson, J. and J.W. Kelly. 1990. Effect of copper sulfate filters on growth of bedding plants. HortScience 25:1144. (Abstr.)

Heins, R. and J. Erwin. 1990. Understanding and applying DIF. Greenhouse Grower 8(2):73-78. Kramer, P.J. 1983. Water relations of plants. Academic, New York.

Latimer, J.G. 1991. Growth retardants affect landscape performance of zinnia, impatiens, and marigold. HortScience 26:557-560.

McMahon, M.J. and J.W. Kelly. 1990. Influence of spectral filters on height, leaf chlorophyll, and flowering of Rosa xhybrida 'Meirutral'. J. Environ. Hort. 8:209-211.

Mortensen, L.M. and E. Stromme. 1987. Effects of light quality on some greenhouse crops. Scientia Hort. 33:27-36.

Orton, P.J. and T.A. Mansfield. 1976. Studies of the mechanism by which daminozide (B-nine) inhibits stomatal opening. J. Expt. Bot. 27:125133.

Rajapakse, N.C. and J.W. Kelly. 1992. Regulation of chrysanthemum growth by spectral filters. J. Amer. Soc. Hort. Sci. 117:481-485.

Rajapakse, N.C., M.J. McMahon, and J.W. Kelly. 1993. End of day far-red light reverses height reduction of chrysanthemum induced by $\mathrm{CuSO}_{4}$ spectral filters. Scientia Hort. 53:249-259.

Roth-Bejerano, N. and C. Itai. 1981. Involvement of phytochrome in stomatal movement: Effect of blue and red light. Physiol. Plant. 52:201-206.

Starman, T.W., J.W. Kelly, and H.B. Pemberton. 1990. The influence of ancymidol on morphology, anatomy, and chlorophyll levels in developing and mature Helianthus annuus leaves. Plant Growth Regulat. 9: 193-200.

Steinberg, S.L., J.M. Zajicek, and M.J. McFarland. 1991a. Short-term effect of uniconazole on the water relations and growth of Ligustrum. J. Amer. Soc. Hort. Sci. 116:460-464.

Steinberg, S.L., J.M. Zajicek, and M.J. McFarland. $199 \mathrm{lb}$. Water relations of hibiscus following pruning or chemical growth regulation. J. Amer. Soc. Hort. Sci. 116:465-470.

Wang, Y.T and L.L. Gregg. 1989. Uniconazole affects vegetative growth, flowering, and stem anatomy of hibiscus. J. Amer. Soc. Hort. Sci. 114:927-932. 